\title{
Over Reliance on Specific Disease Programmes - Are we in the Right Direction?
}

\author{
Sonali Sarkar
}

\section{Sonali Sarkar \\ Additional Professor of PSM, JIPMER, Puducherry - 605006, INDIA.

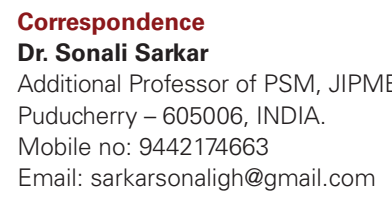

DOI : 10.5530/ijmedph.2017.4.37

Article Available online

http://www.ijmedph.org/v7/i4

\section{Copyright}

(C) 2017 Phcog.Net. This is an openaccess article distributed under the terms of the Creative Commons Attribution 4.0 International license.
Public health in India remains an enigma with evernew challenges emerging in control of communicable diseases and burden of non-communicable disease also on the rise. Since independence 70 years ago, India has achieved major milestones in public health, but on many fronts we are still lacking as compared to the progress made in other countries similar to ours in the level of income and population size. China with a population larger than India has better health indicators and has done much better than India in achieving the Millennium Development Goals (MDG). ${ }^{1}$ As for the achievement of MDG, India ranks the lowest among the BRICS (Brazil, Russia, India, China and South Africa) countries. ${ }^{1}$ With the new Sustainable Development Goals (SDG) set for 2030, the path ahead for India is not easy. It is time that we introspect our approach towards public health in India and try to improve the health of the millions who have been bereft of the benefits from the growth story of the country and left impoverished because of health related expenditures. ${ }^{2}$ In an attempt to discuss some major shortfalls in our health planning, this article will deal with the issue of specific disease programmes in improving public health in India.

In the history of public health in India, the Report of the Health Survey and Development Committee 1946, led by Sir Joseph Bhore is considered the most comprehensive and in-depth understanding of the health situation of the then India and the recommendations are considered to be the harbinger of the concept of Primary Health Care (PHC). It is unfortunate that in spite of rapid progress in many fields of science and technology, health scenario especially in the rural areas of large parts of India still remains unchanged and added to it is problems of the ever increasing slums in the rapidly expanding urban economy. Overall the health situation of large sections of Indian population still remains grim. As realized time and again the recommendations of Bhore Committee whenever revisited are still found relevant. The committee had recognized, also reiterated later by Primary Health Care (PHC) 1978, the role of other sectors like nutrition, agriculture, industries and development of village roads and rural communication on health of the population. ${ }^{3}$ But, these being beyond the scope of the health sector, we now discuss what should be done within the health planning towards achieving Universal Health Coverage (UHC).

For health planning, Bhore Committee had recommended the policy of Govt of United Kingdom (UK), which has led to one of the most successful models of health services in the world. The report states "the ideal to be aimed at by National Health Services cannot be better stated than by the Ministry of Health in the UK. The new service is designed to provide for everyone who wishes to use it, a full range of health care. It must offer as and when required, the care of a family doctor, the skills of a consultant, laboratory service, treatment in hospital, advice and treatment available in specialized clinics (maternity and child welfare, tuberculosis dispensaries and the like), dental and ophthalmic treatment, drugs and surgical appliances, midwifery, home nursing and all other services essential to health. Moreover, all these branches of medical care must be so planned and related to one other that everyone who used the new service is assured of ready access to whichever of its branches he or she needs." ${ }^{3}$ What was endorsed in the UK was a comprehensive care involving both general and speciality services, facility and home based care and specialized services from all branches of medicine integrated and easily accessible to all. These ideal services were proposed to be catered to people through Primary units, Secondary unit headquarters and District headquarters, ${ }^{3}$ which later became Primary Health Centre, Community Health Centre and District Headquarter hospitals. Depending on the population density and the area to be covered, a Primary unit for every 10,000 to 20,000 population was recommended to have 6 Medical Officers, 78 non-medical staff and 75 beds. Seventy years since this report, the population of India has grown nearly four times, but the number of beds available is not even $7 / 10,000$ compared to $75 / 10,000$ recommended. ${ }^{4}$

From the beginning of health planning in India, the focus has been on tackling the major challenges like population control and causes of high mortality and morbidity through programmes targeting those specific conditions in a vertical approach. To deal with high mortality conditions, selective PHC, better known as the vertical approach, is preferable. ${ }^{5}$ Thus were launched vertical and semi-vertical programmes like child survival, safe motherhood, small pox eradication, National Malaria Eradication 
Programme, National Leprosy Eradication programme and National Tuberculosis Programme among many others. Introduction of such programmes and modification and renaming of existing programmes continue till date with the changing epidemiology of diseases and their risk factors. What should have been the short-term plan with simultaneous development of the health system and strengthening of the PHC as the long-term goal did not happen.

As outcome of the specific disease programmes showed promising results, the prospective governments and five-year plans continued with the vertical approach till the National Rural Health Mission (NRHM) in 2005 , brought in some decentralization and integration of the programmes under one umbrella and also focused on the dire need of strengthening the health infrastructure and overall the system. But in reality the process of decentralization and integration is far from complete. The result is that the initial gains from the specific disease programmes have now stagnated and further success in control of diseases can be brought about only through improvement in the health system, especially the health infrastructure and health manpower. The pace of decline in some key indicators like Infant Mortality Rate (IMR), Neonatal Mortality Rate (NMR), Maternal Mortality Ratio (MMR) and prevalence and incidence of infectious diseases like Tuberculosis (TB) has slowed down in the past one decade. ${ }^{6}$ For TB, the estimates of prevalence and incidence as reported by the Govt. of India were revised after the research on the sale of anti-tubercular drugs in the private sector. This suggests that the burden has not come down, partly because of weaknesses in the public health system. Incidence in 2016 is $217 /$ lakh population as compared to 216/lakh in $1990 .^{7}$ Further decline in the morbidity and mortality rates will depend on how good is the health system in responding to the health problems of the population in a comprehensive manner as quoted by the Bhore Committee Report.

In 2008, on the 30th anniversary of the Alma-Ata declaration, revitalization of PHC was identified as the way forward for achievement of the MDG and UHC. The conference on Revitalization of PHC held in Jakarta in 2008 identified two reasons for not being able to provide the comprehensive $\mathrm{PHC}$ as the i) training of physicians being more focused in medical science and technology and not towards public health and ii) limited human and financial resources for health. ${ }^{6}$ Both are likely reasons for still adopting single disease programmes in India. Problem with the vertical approach is that the care is fragmented and compartmentalized without focus on the individual or the family. There is no relation between the services under each of the programmes, the services provided and maintenance of records being specific to the programme. When a pregnant woman in India suffers from TB, the information about TB is neither recorded in her antenatal card nor the information of her pregnancy in her TB treatment card. It is said that "narrow focus of many disease control programmes discourage a holistic approach to the individuals and the families they deal with and do not appreciate the need for continuity in care". Also, the specific disease programmes are mostly based on secondary prevention measures and clinical or medical interventions like early diagnosis and treatment for malaria, leprosy, TB, and even tertiary interventions for cancer control programme. Health impact of the long lasting protective interventions as in the $\mathrm{PHC}$ are proven to be greater than the clinical interventions. ${ }^{9}$ Therefore this vertical approach of specific disease health programmes clearly contradicts the concept of $\mathrm{PHC}$ to which India was also a signatory. "Acceptance of PHC implied the organization of rest of the health system so as to provide support for PHC and enhance its further development, which means health system as a whole has to accept the social goal of making essential health care available to all". ${ }^{10}$ This essential health care is still not available to many in the country - even to date $21 \%$ of all deliveries in India are happening at home ${ }^{11}$ without the assurance of aseptic conditions. Thus indicating that, the specific disease programmes are not the solution to India's multitude health problems. These single disease programmes or selective $\mathrm{PHC}$ have even been considered a threat and counter-revolution by some. ${ }^{5}$

"Many Low and Middle Income Countries have now realized this and are now moving from narrow specific disease control interventions to a wider perspective of integrated and comprehensive multi- sectoral interventions for health development" ${ }^{12}$ The theme of World Health Report - 2008, PHC (Now More Than Ever), ${ }^{8}$ still holds good for India. Gains from secondary and tertiary health care, interventions in the vertical approach is more appealing to the people, but, it is the investment in PHC that will bring health, social and economic gains to the country. Now that we are still far from the health related MDG and have committed ourselves to SDG, a revised approach towards health planning in India is urgently needed. With low levels of public health spending, health budget should be used wisely in restructuring and strengthening the PHC so as not to look for short-term benefits but invest in the healthier future of the country.

\section{REFERENCES}

1. Fullman N, Barber RM, Abajobir AA, Abate KH, Abbafati C, Abbas KM, et al. Measuring progress and projecting attainment on the basis of past trends of the health-related Sustainable Development Goals in 188 countries: an analysis from the Global Burden of Disease Study 2016. The Lancet. 2017;390(10100):1423-59

2. Garg C, Karan A. Reducing Out-Of-Pocket expenditures to reduce poverty: a disaggregated analysis at rural-urban and state level in India, Health Policy and Planning. 2007;17:1-13.

3. Bhore J, Amesur RA, Banerjee AC. Report of the health survey and development committee. Vol II: 1-508 [Internet]. [cited 2017 Nov 23]. Available from https://www.nhp.gov.in/sites/default/files/pdf/Bhore_Committee_Report_VOLII.pdf

4. The World Bank (2014) [Internet]. Hospital beds (per 1,000 people) [cited 2017 Nov 23]. Available from http://data.worldbank.org/indicators/SH.MED.BEDS ZS? locations =IN;

5. World Health Organization [Internet]. Regional Conference on Revitalizing Primary Health care; 2008 Aug 6-8, Jakarta, Indonesia. [cited 2017 Nov 23]. Available from www.who.int/ management/ district/ RevitalizingPHC2008SEARO. pdf

6. Ministry of Statistics and Programme Implementation (MOSPI) [Internet]. MilIennium Development Goals India Country Report 15. [cited 2017 Nov 23]. Available from http//mospi.nic.in /Mospi_new/ upload/ mdg.

7. World Health Organization [Internet]. Global Tuberculosis Report 2017 [cited 2017 Nov 23]. Available from; www.who.int/tb/publications/global_report/ gtbr2017_executive_summary.pdf

8. World Health Organization [Internet]. The World Health Report 2008-Primary Health Care. [cited 2017 Nov 23]. Available from www.who.int/whr/2008/ whr08_en.pdf.

9. Thomas RF. A Framework for Public Health Action: The Health Impact Pyramid. Am J Public Health. 2010;100(4):590-95.

10. World Health Organization [Internet]. International Conference on Primary Health Care; 1978; Alma-Ata, USSR. [cited 2017 Nov 23]. Available from www. who.int/Publications/almaata_declaration_en.pdf

11. NFHS-4 (National Family Health Survey-4) [Internet]. International Institute for Population Studies. 2016. [cited 2017 Nov 23]. Available from http://www.iipsindia.org or http://www.mohfw.nic.in

12. Sien T. Oxford Textbook of Global Public Health. $6^{\text {th }}$ ed. Detels R, Gulliford M, Karim QA, Tan CC editor. New York: Oxford University Press; 2011. 